\title{
UNA NUEVA COPIA DE MURILLO POR JOSÉ MARÍA ESCACENA Y DAZA
}

\section{A MURILLO'S NEW COPY BY JOSÉ MARÍA ESCACENA Y DAZA}

\author{
Álvaro Cabezas García \\ IES Alixar, Castilleja de la Cuesta. España \\ alvarocabezasgarcia@gmail.com
}

\begin{abstract}
El pintor José María Escacena y Daza, conocido por sus cuadros de temática costumbrista y orientalista, realizó la copia inédita que aquí se presenta de Los niños de la concha de Murillo en 1820, cuando aún desarrollaba su aprendizaje en la Real Escuela de las Tres Nobles Artes de Sevilla. Posiblemente esta sea la obra más temprana de su producción.

Palabras clave: Pintura; Sevilla; Murillo; copia; José María Escacena y Daza.
\end{abstract}

This paper release an unpublished copy of Murillo's Los niños de la concha made by the painter José María Escacena y Daza, known for his paintings of customs and orientalism themes, in 1820, when he still developing his learning at the Royal School of the Three Fine Arts of Seville. Possibly this is the earliest work of his catalogue.

Keywords: Painting; Seville; Murillo; copy; José María Escacena y Daza.

En una colección particular sevillana se conserva un lienzo de $104 \mathrm{~cm}$ de alto y 127 de ancho hasta ahora desconocido por la historiografía (Figura 1). Ofrece algún interés al estar firmado por el pintor José María Escacena y Daza (Sevilla, 1800-1858). Efectivamente, en el reverso, y entre los bastidores, figura la siguiente inscripción "En Sevilla. Año de 1820. Es de José Ma . Escazena, Copia de la q' hizo Bayeu pr el original de Murillo q.e esta en el R1. Palacio de M.d". En medio de la misma se aprecia otro grafismo que parece aportar una fecha posterior a la de realización: "1852" (Figura 2). La pintura es copia de la conocida obra Los niños de la concha (c. 1670, 104 x 124 cm, Museo Nacional del Prado), de Bartolomé Esteban Murillo (Sevilla, 1617-1682), pero, a tenor de la inscripción, se realizó a partir de una reproducción acometida por Francisco Bayeu y Subías (Zaragoza, 1734-Madrid, 1795) del original conservado en ese periodo en el Palacio Real de Madrid $^{1}$. Las diferencias más notables son aquellas que marcan la distancia entre

${ }^{1}$ Esta pintura fue una de las que la reina Isabel de Farnesio adquirió en Sevilla durante el Lustro Real (1729-1733) y llevó a Madrid con posterioridad. Se tiene constancia de 
la calidad de uno y otro pintor, pero el formato, las medidas y la composición se mantienen idénticos. No obstante, la plasmación de los colores utilizados es mucho más fría y, si bien Escacena ha conseguido reproducir hasta los detalles más nimios -repárese en el vuelo de la filacteria de la cruz del Bautista-, no ha logrado dotar a los rostros de la candidez y delicadeza que rezuman del original de $\mathrm{Mu}$ rillo, sino inflamándolos de la blandura y sentimentalismo con que se asociaba el estilo del pintor del seiscientos durante buena parte del siglo XIX ${ }^{2}$. Un aspecto en el que también difieren es en la recreación del ambiente espacial. Si en Murillo el lugar donde los infantes se hallan parece un claro en medio de un frondoso bosque por el que transcurre el Jordán, abierto levemente entre penumbras, en la copia de Escacena están delimitados los distintos espacios con escasa imaginación y el claro se aprecia de manera más áspera entre árboles, nubes y rocas, amén de no incluir algún elemento vegetal que sí aparece en la obra primigenia.

Sobre Escacena se conocen los datos que lo engloban profesionalmente en su medio artístico como profesor de la Real Escuela de las Tres Nobles Artes y académico de la de Bellas Artes de Santa Isabel de Hungría ${ }^{3}$. La veintena de obras que hoy se tienen como de su mano oscilan entre la copia murillista de El Bautismo de Cristo (1826) ${ }^{4}$, o esta que aquí se estudia, hasta el desarrollo de las escenas de costumbres que tan apreciadas fueron en exposiciones o en colecciones particulares

su permanencia en el Palacio de La Granja en 1746, en el de Aranjuez en 1794, en el Palacio Real en 1814 y en el Museo del Prado desde 1819. Vid. VALDIVIESO, Enrique (com.): $M u$ rillo. Pinturas de la colección de Isabel de Farnesio en el Museo del Prado. Sevilla, 1996, p. 86.

${ }^{2}$ El más acertado análisis de esta opción estética es el de Alfonso E. Pérez Sánchez: "Pero esa influencia, tanto pictórica como literaria, mostrará sin embargo, casi siempre, una incomprensión profunda del espíritu murillesco, pues sustituirá la visión directa, y en cierto modo gozosa, del pintor sevillano, por una actitud ternurista, paternalista y compasiva de tono sentimental". Cfr. Ibidem, p. 18.

${ }^{3}$ Siguiendo los pasos de su padre, Juan Escacena ( $\left.† 1814\right)$-único pintor sevillano que permaneció activo durante la ocupación francesa y que había colaborado con Vicente Alanís en los adornos con que la ciudad recibió a Carlos IV y a María Luisa de Parma en 1796-, José María ingresó en la Real Escuela de las Tres Nobles Artes de Sevilla muy joven y ulteriormente obtuvo dos premios, uno en 1829 en la sala del Natural, que le valió para recibir el Diccionario de Ceán Bermúdez como recompensa, y otro en 1830 y por la misma disciplina. Comenzó entonces a trabajar como profesor en la institución. Según Ossorio y Bernard, fue nombrado teniente director de pintura desde 1829, encargándose de la clase de Colorido y Composición hasta la fecha de su fallecimiento. En 1850 pasó a ser académico de Santa Isabel de Hungría de Sevilla, cuando la primitiva institución derivó en Academia. Allí se mantuvo hasta su muerte en 1858. MURO OREJÓN, Antonio: Apuntes para la historia de la Academia de Bellas Artes de Sevilla. Sevilla, 1961, pp. 54, 55, 71, 74, 170, 183, 202 y 232; y OSSORIO Y BERNARD, Manuel: Galería biográfica de artistas españoles del siglo XIX. Madrid, 1868, p. 198.

${ }^{4}$ Fue dada a conocer por ROS GONZÁLEZ, Francisco S.: "El Bautismo de Cristo de José María Escacena y Daza, una copia de Murillo”, Laboratorio de Arte, 24, 2012, pp. 537-548. 
como la de los duques de Montpensier ${ }^{5}$. No hay que olvidar la importante faceta que desarrolló como pintor de temas orientales: su padre introdujo decoración de tipo moruno en la casa de los Cavaleri ${ }^{6}$ mientras estaba ocupada por el general Gazan y él, siguiendo seguramente sus enseñanzas, fue considerado uno de los precursores de este género en España ${ }^{7}$, sobre todo a partir del viaje que realizó a Marruecos al menos en dos ocasiones: 1834 -en compañía de David

${ }^{5}$ Se trata de dos pinturas con el mismo título, Dos pilluelos jugando a los naipes, procedentes de la colección de los Montpensier tras ser expuestas en la Exposición Agrícola, Industrial y Artística de Sevilla de 1858. En ellas Escacena adapta las formas utilizadas en las pinturas de tema profano de Murillo Niños comiendo melón y uvas y Niños jugando a los dados a la pintura digna de coleccionistas, sobre todo extranjeros, ávidos por llevarse de Sevilla obras que representaran tipos populares como los pilluelos que identificaban con la ciudad. Fueron registradas en el Catálogo de los cuadros y esculturas pertenecientes á la Galería de SS. AA. RR. los Serenísimos Señores Infantes de España, Duques de Montpensier. Sevilla, 1866, p. 56. DE LA BANDA Y VARGAS, Antonio: "Catálogo de la Colección Artística de la Infanta Doña Luisa de Orleans", Anales de la Universidad Hispalense, 1957-1958, p. 34; VALDIVIESO, Enrique: Pintura sevillana del siglo XIX. Sevilla, 1981, pp. 33-34; VALDIVIESO, Enrique: Historia de la pintura sevillana: siglos XIII al XX. Sevilla, 1986, p. 365; PÉREZ CALERO, Gerardo: "La Exposición Agrícola, Industrial y Artística de Sevilla de 1858”, Laboratorio de Arte, 9, 1996, p. 204; y RODRÍGUEZ REBOLLO, Ángel: Las colecciones de pintura de los duques de Montpensier en Sevilla (1866-1892). Madrid, 2005, p. 65. Ha quedado reflejado como el pintor David Wilkie y el literato Washington Irving permanecieron en Sevilla ávidos por encontrar fígaros y rosinas. Cfr. GARCÍA FELGUERA, María de los Santos: La fortuna de Murillo. Sevilla, 1989, p. 63. Richard Ford, residente en Sevilla entre 1830 y 1833, imaginaba en sus visitas al barrio de la Macarena y al Corral del Conde la presencia de Murillo para recrear el ambiente popular que allí había. Cfr. CABEZAS GARCÍA, Álvaro: Teoría del gusto y práctica de la pintura en Sevilla (1749-1835). Sevilla, 2015, p. 314.

${ }^{6}$ Vid. OLLERO LOBATO, Francisco: "La ocupación francesa de Sevilla y la difusión del neoclasicismo: la decoración de la casa de los Cavaleri”, Laboratorio de Arte, 15, 2002, pp. 189-199.

${ }^{7}$ De esa temática son sus pinturas Pastor árabe, Paisaje africano con tienda de campaña, Retrato del Cid Mustafá el Hesany, Ante una casa, Marruecos y A la entrada de un café marroquí. Casi todas habían pertenecido a la colección Montpensier y fueron realizadas durante el viaje por Marruecos en 1834 o en años siguientes. Cfr. ARIAS ANGLÉS, Enrique: "Escacena y Daza, pionero del orientalismo romántico español", Archivo Español de Arte, 1999, pp. 279-287; ARIAS ANGLÉS, Enrique: "La visión de Marruecos a través de la pintura orientalista española”, en DE FELIPE, Helena (coord.): Imágenes coloniales de Marruecos en España, Dossier des Mélanges de la Casa de Velázquez, 37-1. Madrid, 2007, pp. 14-16; PASTOR GARRIGUES, Francisco Manuel: "La presencia española en Marruecos", Revista de Occidente, 395, 2014, p. 121; y DIZY CASO, Eduardo: Los orientalistas de la escuela española. París, 1997, p. 80. Con independencia de que Escacena tomase apuntes del natural mientras estuvo en Marruecos, varios de estos cuadros los realizó, firmó y dató algo después en Gibraltar. Allí ejecutó los lienzos $E l 79^{\circ}$ regimiento de los Montañeses en 1841 en Gibraltar y Escocés tocando la gaita, hoy conservados en The Highlander's Museum-Queen's Own Highlanders Collection de Inverness, en Escocia. 
Roberts (1796-1864) - , y 1839 - con John Drummond Hay (1816-1893)-. Además, en los últimos años se han conocido algunas pinturas de floreros y retratos de su mano ${ }^{9}$. Aspectos interesantes derivados de su actividad son su labor como decorador de adornos efímeros ${ }^{10}$, agente artístico $^{11}$, coleccionista $^{12}$, restaurador de pinturas ${ }^{13} \mathrm{o}$, incluso, guía turístico ${ }^{14}$.

${ }^{8}$ Escacena escribe a la Real Academia de Bellas Artes de San Fernando en 1851 informándole del envío de cuatro pinturas suyas para que fueran sometidas al examen de la corporación. Uno de los cuadros "fue pintado por mi en Tanger en 1834 y representa dos gefes Arabes”. Vid. ARIAS ANGLÉS, Enrique: El paisajista romántico Jenaro Pérez Villaamil. Madrid, 1986, pp. 47-48 y p. 508, doc. 193.

${ }^{9}$ Con respecto a los retratos, se trata de los de Alonso Cano, conservado en la sede de la Real Academia de Bellas Artes de Santa Isabel de Hungría, y Félix José Reinoso, en la Biblioteca Colombina de la catedral de Sevilla, según copia de José Gutiérrez de la Vega, ambos firmados en 1851. Vid. VALDIVIESO, E.: Historia de la pintura sevillana, op. cit., p. 365. A estos habría que añadir el de George William Drummond Hay and Francis Drummond Hay, de 1833 y subastado en Reino Unido en 1992, y el Retrato de un niño, fechado en 1853 y conservado en colección particular. Vid. FERNÁNDEZ LÓPEZ, José y VALDIVIESO, Enrique: Pintura romántica sevillana. Sevilla, 2011, p. 99. Con respecto a los floreros, además del que se presentó algunos años tras su fallecimiento en la Exposición Universal de Londres de 1862, hay que añadir los dos trampantojos de racimos de uva que Francisco Ros señaló como subastados en Arte, Información y Gestión en 2011. ROS GONZÁLEZ, F. S.: "El Bautismo...", op. cit., p. 541.

${ }^{10}$ Escacena realizó varios trabajos pictóricos imitando bajorrelieves en las exequias celebradas en Sevilla por la reina María Josefa Amalia de Sajonia en 1829. Cfr. OSSORIO Y BERNARD, M.: Galería biográfica..., op. cit., p. 198.

${ }^{11}$ Escacena fue uno de los profesionales que, junto con José Bueno, José Antonio de Mesa y Diego Monroy, vendieron al barón Taylor obras de sus colecciones particulares y actuaron como intermediarios, tanto en Sevilla como en Cádiz, para la compra de cuadros o restauraron pinturas que después fueron llevadas a París entre 1835 y 1837 . Vid. VIGARA ZAFRA, José Antonio: "La galería española de Luis Felipe de Orleáns y sus vinculaciones con el patrimonio pictórico de Córdoba", Boletín de Arte, 32-33, 2011-2012, pp. 655 y 657, donde se transcriben algunos recibos de Escacena conservados en París y donde se detallan las relaciones con otro importante personaje como el vicecónsul Julian Benjamin Williams.

${ }^{12}$ CÓMEZ RAMOS, Rafael: "Coleccionistas de pintura en Sevilla en 1842", Laboratorio de Arte, 5, 1993, pp. 159-165, analiza lo apuntado por la Noticia de los principales monumentos artísticos de 1842: que tenía taller en la calle Colcheros con un enorme "museo" de pinturas de más de 3.000 cuadros, tanto de escuela sevillana como de otras.

${ }^{13}$ Restauró en 1828 la Liberación de San Pedro de Juan de Roelas con motivo de la hechura de un nuevo retablo para la capilla de San Pedro ad Vincula de la parroquia de San Pedro. Vid. ROS GONZÁlEZ, Francisco S.: "La liberación de San Pedro, una obra inédita del pintor Francisco Miguel Ximénez", Laboratorio de Arte, 21, 2008-2009, pp. 451-459; y ROS GONZÁLEZ, Francisco S.: "Los retablos de Juan de Astorga", Laboratorio de Arte, 17, 2004, p. 302.

${ }^{14}$ Al menos actuó así para John Drummond Hay, tal y como asegura en DRUMMOND HAY, J. H.: Western Barbary: Its wild tribes and savage animals. Londres, 1844, p. 5. 
La obra que aquí se aporta sería, por tanto, la primera por cronología de todas las conocidas hasta ahora dentro de su escaso catálogo. Podría explicarse como una de las prácticas en las que la Real Escuela apoyaba la evaluación de la formación de los pintores en ciernes que estaban matriculados en ella. Así parece indicarlo el extenso grafismo de la autoría, en el que se detalla no solo quien lo realiza sino los medios exactos de los que se ha servido, además de la fecha, tal y como si fuera necesario aportar esta información para diferenciar esta pintura de otras de parecida temática o factura prestas a juzgarse por terceras personas, en este caso, los profesores de la Real Escuela ${ }^{15}$.

La copia de Murillo había sido una constante en Sevilla casi desde el mismo momento de la desaparición del pintor y alcanzó un desarrollo extraordinario a lo largo de los dos siglos siguientes ${ }^{16}$. Con la inclusión de la ejecución de estas copias en el plan de estudios de la Real Escuela se perseguían dos objetivos: primero, servir al activo sector promotor que reclamaba inequívocamente continuar la ejecución de obras pictóricas con el estilo de Murillo - algo que aun se incrementó más tras la francesada $-{ }^{17} \mathrm{y}$, segundo, restituir el buen nombre de las artes en Sevilla de la mano del que consideraban su pintor predilecto ${ }^{18}$. Algunas de las copias se hicieron in situ y de manera organizada ${ }^{19}$. Sin embargo, en casos como este, en que el original se encontraba fuera de Sevilla, era necesario recurrir a referencias literarias, grabados y copias como la referida de Bayeu.

${ }^{15}$ En 1820 el director de la clase de Pintura de la citada corporación era Joaquín María Cortés y su tenencia era ocupada por Andrés Rosi. Estos serían, seis años después del fallecimiento de su padre, los encargados de la instrucción recibida por José María Escacena. Cfr. MURO OREJÓN, A.: Apuntes para la historia..., op. cit., p. 142.

16 Tomás Martínez fue el primer copista de Murillo. Cfr. VALDIVIESO, Enrique: Pintura barroca sevillana. Sevilla, 2003, p. 398.

${ }^{17}$ La posesión de obras de Murillo era un motivo de estima social, un paradigma de prestigio. Así lo explica ÚBEDA DE LOS COBOS, Andrés: Pensamiento artístico español del siglo XVIII: de Antonio Palomino a Francisco de Goya. Madrid, 2001, p. 333.

${ }^{18} \mathrm{La}$ Real Escuela, formada en origen por los discípulos del murillista Domingo Martínez, consiguió la aprobación real tras alegar que iban a continuar con la institución fundada por Murillo y otros artistas en 1660 en el edificio de la Lonja. Así lo pusieron por escrito tanto Francisco Bruna ante el marqués de Grimaldi en 1770. Vid. ROS GONZÁLEZ, Francisco S.: "La fama de Murillo y las copias de los lienzos del Hospital de la Santa Caridad", en Estudios sobre Miguel Mañara. Su figura y su época, santidad, historia y arte. Sevilla, 2011, pp. 321-352. Como años más tarde Joaquín Cortés ante las Cortes de Cádiz. Vid. MURO OREJÓN, A.: Apuntes para la historia..., op. cit., pp. 6 y 7.

${ }_{19}$ Bruna se dirigió en 1782 al hermano mayor de la Caridad con la solicitud de que se permitiera colocar unos andamios para copiar las pinturas de Murillo que allí se conservaban. En ese momento, el padre de José María Escacena, Juan Escacena, realizó una copia de Abraham y los tres ángeles depositada hoy en el colegio mayor Hernando Colón. Espinal y Alanís también hicieron lo propio. En 1788 hubo otro plan de copias. La noticia la da ROS GONZÁLEZ, Francisco S.: "La fama de Murillo...”, op. cit., pp. 330-333. 
Así surgió, de la mano sin voluntad de la memoria de Murillo, la realidad del casticismo: el tipismo y su consecuencia en la pintura, el costumbrismo. Murillo, propuesto por los ilustrados como una solución de calidad en el siglo XVIII capaz de satisfacer el buen gusto de la clientela y ser útil para la resurrección de la pintura, aparece ya en el XIX como un símbolo de identidad estética en Sevilla, del que solo cabe la imitación, o como mínimo, la marcada inspiración para alcanzar la aprobación y conseguir el éxito. Murillo fue el principal pintor de toda la centuria. Su espíritu pintó como nunca, y con esto se quiere decir que decantó el estilo y colmó las pretensiones profesionales de todos los pintores del siglo, quienes habían de tenerlo permanentemente como referencia para satisfacer la evaluación de los enseñantes de la Real Escuela primero y las demandas clientelares después.

A tenor de las obras conocidas, José María Escacena solo realizó copias de Murillo en su etapa formativa en la Real Escuela. Tras ese periodo se dedicó, siempre siguiendo el ideal estético murillista, a componer escenas de género o retratos y a concursar en exposiciones y certámenes. Su amistad con importantes personajes de la época -Williams, Roberts o Drummond Hay-, todos ellos extranjeros, le permitió viajar al norte de África e inaugurar así una nueva vía de expansión pictórica e inusitado éxito en las décadas siguientes: el orientalismo, es decir, la adaptación del costumbrismo local a los ámbitos exóticos sobre los que pusieron el foco los "curiosos impertinentes" 20 . Pero, además de eso -y como en este estudio se ha señalado-, utilizó las mismas soluciones para representar escenas de destacamentos militares del ejército escocés o paisanos de esta región vestidos con su atuendo tradicional. Por consiguiente, en la obra de Escacena se testimonia no solo una activa atención a las necesidades del mercado artístico, sino una completa sincronía con las tendencias pictóricas internacionales del momento histórico que le tocó vivir. Consiguió utilizar su formación sevillana, deudora insistente de la autorreferencia de Murillo, para el adelanto de géneros pictóricos determinantes en el panorama estético de las décadas posteriores.

Fecha de recepción: 30 de septiembre de 2016

Fecha de aceptación: 31 de enero de 2017

${ }^{20}$ El primero que los llamó así, utilizando la expresión cervantina, fue ROBERSTON, Ian: Los curiosos impertinentes. Viajeros ingleses por España 1760-1855. Madrid, 1976. 


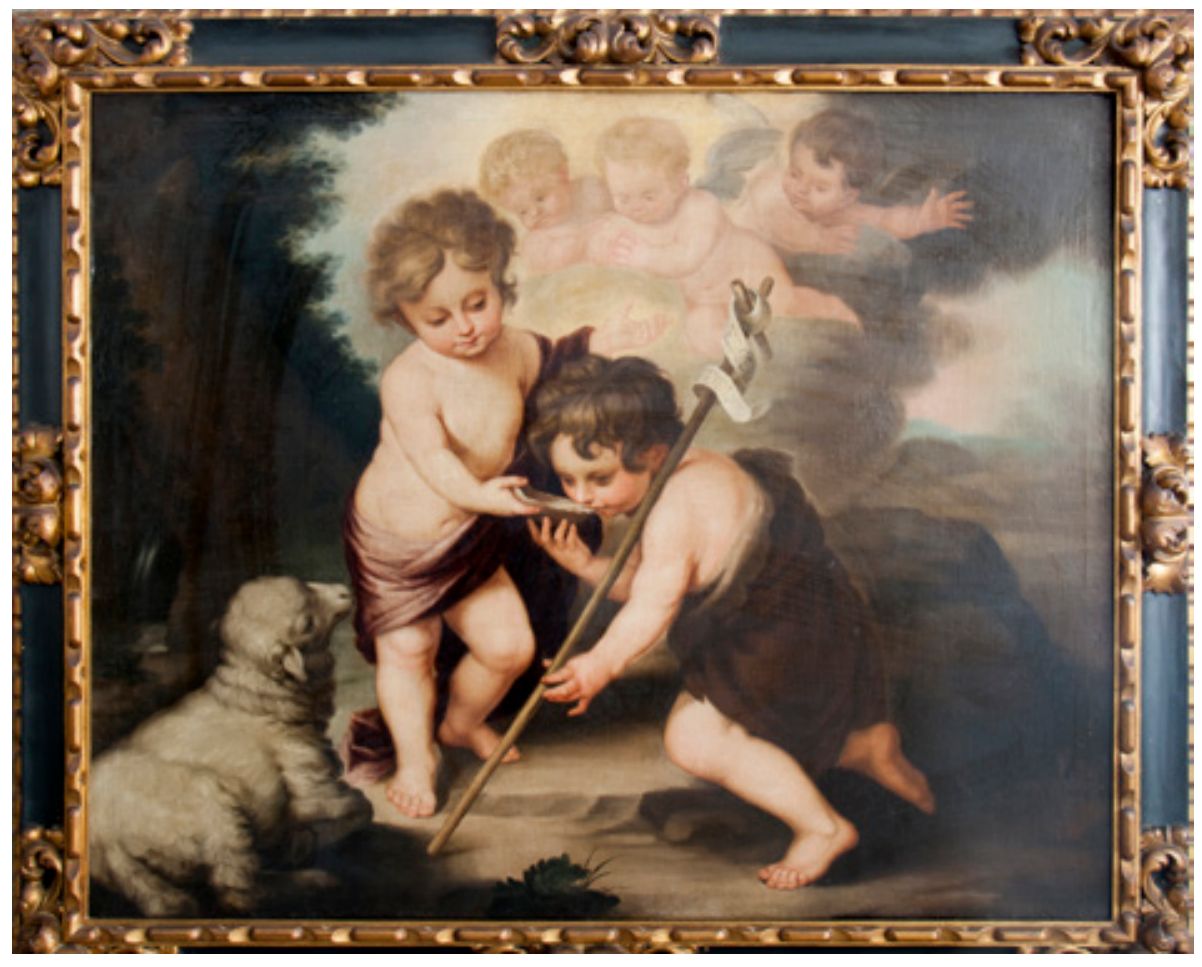

Figura 1. José María Escacena y Daza, Los niños de la concha (copia del original de Murillo y de una copia de Bayeu), 1820, colección particular, Sevilla. 


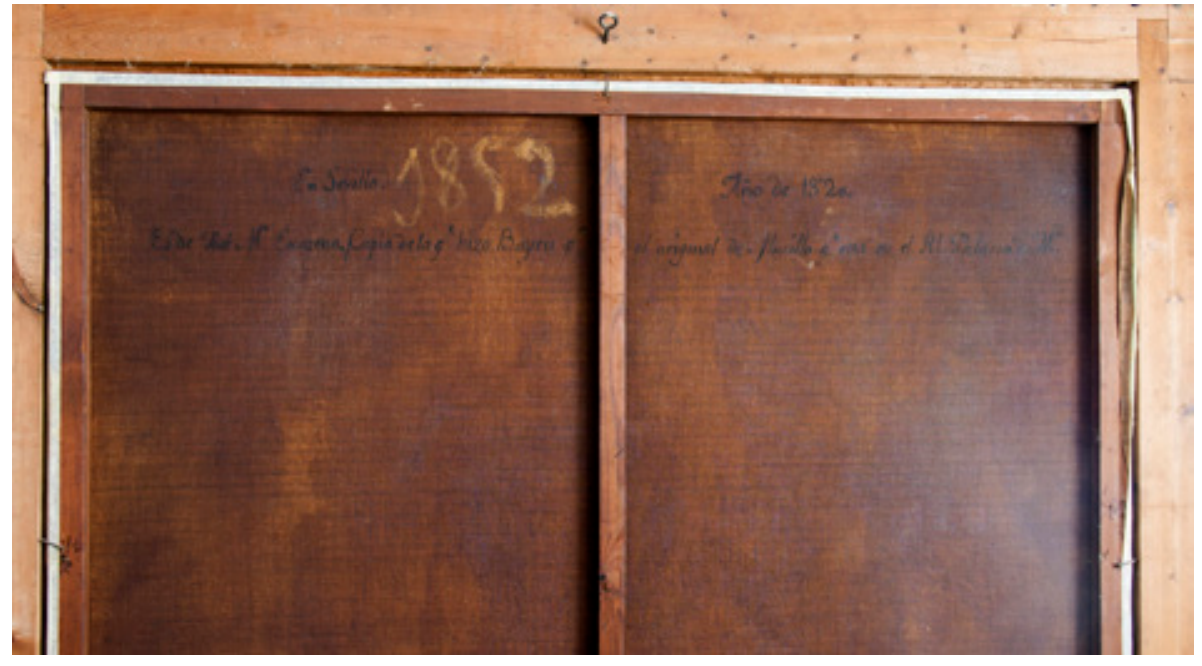

Figura 2. José María Escacena y Daza, Los niños de la concha (detalle de la inscripción), 1820, colección particular, Sevilla. 